\title{
PALESTRA
}

\section{CONECTANDO ÉTICA E ESTÉTICA: REFLEXÕES SOBRE O DESIGN}

\section{Maria Cecília Loschiavo dos Santos}

Faculdade de Arquitetura e Urbanismo da Universidade de São Paulo

closchia@usp.br

No mundo contemporâneo em que vivemos, os tempos são de incertezas, conflito e crise ambiental aguda $\mathrm{O}$ design é protagonista de todos estes fenômenos. Ao encerrar este tradicional encontro de nossa área do conhecimento, gostaria de apresentar alguma ideias sobre o papel de pesquisa em design e o fortalecimento do espírito crítico neste contexto desafiador.

Numa entrevista recente, Gui Bonsiepe foi perguntado sobre 'quanto de teoria do design necessita no dias atuais'. De forma inequívoca respondeu: ' Se você pode entender a teoria como espaço de reflexão crítica, então ela é indispensável, dado o corrente e hegemônico, discurso de mão única do mercado. Não se trata de teoria no sentido de especulação não-concomitante, removida do empírico, mas no sentido de reflexão ligada à fatualidade'. (design/ssues: volume 31, Number 1 Winter 2015).

Vejamos os fatos conhecidos e incontestáveis: 1) complexidade crescente da crise ambiental, degradação sistemática do ar, água e solo; crescimento populacional vertiginoso, mormente concentrado nas megacidades e a consequente destruição dos ecossistemas urbanos; 2) deslocamentos populacionais forçados, massivos, rotinas e temporalidades instáveis, contestações, vida neo-nômade; 3) crescimento de desigualdades setoriais, regionais e sociais, além do sensível aumento da população de moradores de rua; 4) fortalecimento da sociedade de consumo, caracterizada pelo hipercosumismo e excessivo descarte, precarização e financeirização das relações sociais e, em especial no atual cenário político do país; 5) descrédito na atuação das instituições públicas e desnorteamento dos rumos da democracia.

Em momentos como estes, é fundamental admitir um distanciamento para reflexão e a mobilização de sofisticado instrumental crítico para produzir os ajustes de rota e construir novos caminhos.

Gostaria de dizer que por muitos anos ouvi perguntas do tipo: 'o que você faz é filosofia do design?' Para que ? Para quem ? Era um discurso sorrateiro que pouco 
entendia sobre design, muito menos sobre filosofia. Ignorava sobretudo, que a mais relevante característica da atitude filosófica é exatamente a crítica e, este foi o maior ensinamento que recebi de meus professores do Departamento de filosofia, da FFLCHUSP. A eles devo apenas não o instrumental e crítico, mas também o paradigma de engajamento da ciência humana. Afinal, como dia o professor Bento Prado Jr., em artigo publicado no caderno 'Mais' da Folha de S. Paulo, de 7/3/1999, de que valeria a ciência, "(...) que não iluminasse nossa experiência atual da cultura e da sociedade, isto é que não se completasse justamente em crítica.'

No espírito da importância da reflexão teórica sobre design, é fundamental retomar Tomas Maldonado, autor de obra inaugural de nosso campo do conhecimento. No ano de 2000, ele surpreendeu a todos os presentes na Conferência Design plus Research, promovido pelo programa de Doutorado do Politécnico de Milão e admitiu ser necessário promover um ajuste no conceito por ele mesmo estabelecido, tendo em vista as transformações decorrentes do desenvolvimento tecnológico, no setores de produção e distribuição, a face aos novos desafios sociais, culturais e ambientais, estimulando pesquisas envolvendo reflexões históricas, filosóficas, econômicas e antropológicas acerca do design.

Maldonado descreveu esse processo de banalização da palavra design, sobretudo operado pela mídia:

'A verdade sobre o assunto, é que a palavra design não é mais confiável. Embora ela seja usada e certamente abusada em quase todos os lugares, essa palavra é tão vaga que se tornou mais e mais irritante, dia a dia. Como ela é aplicada para responder as necessidades programáticas ( e promocionais) de todos os tipos de atividade - o arquiteto, o engenheiro, o designer, o estilista de moda, o cientista, o filósofo, o gerente, o político, o programador, o administrador - a palavra perdeu o seu sentindo de especificidade'.

Maldonado adverte que esse processo de banalização não é apenas uma questão de léxico. Segundo ele, trata-se de uma indeterminação, que parece ser o principal obstáculo para a definição do design como disciplina. Para ele, esse processo provoca efeitos devastadores pois ' quando há falta de definição, nenhuma ação coerente é possível.'

Creio que a banalização, a indeterminação, o uso indiscriminado da palavra design implicam na negação do design como agente de mudança e é esse conceito que considero definidor para a mudança de paradigma do design, no enfrentamento da problemática contemporânea. Sobretudo no contexto em que nos encontramos de pós-industrialização e hiperconsumo, onde todos os produtos parecem já terem sidos criados e produzidos, num contexto onde coexiste o abismo talvez insuperável entre a riqueza e a pobreza absoluta. 
Bonsiepe também revela posicionamento decisivo ao apontar o uso inflacionário da palavra design nos dias atuais. Para ele ' a popularização do termo design durante a década passada, não só nas regiões onde se fala inglês, e o uso mais ou menos inflacionário tornou a palavra design um termo lugar comum que se libertou ele próprio da categoria de projeto, atingindo agora um tipo de existência autônoma' (Gui Bonsiepe (2007)).

Para este autores, pensar a dimensão crítica no âmbito do design, não é apenas reflexo de uma época, mas requer a reconsideração sobre a natureza do design, enquanto prática de projeto. A pergunta sobre a natureza do design, sobre sua essência é indiscutivelmente uma indagação filosófica.

Em entrevista realizada com Bonsiepe, no ano de 1980 perguntei-Ihe sobre a natureza do design, o eu lhe é próprio. A resposta foi certeira:

' A sua tendência de problematizar a relação artefato/usuário. O desenh industrial é uma normativa 'branda'. Definiria o que é específico do desenho industrial, a essência do desenho industrial, como sensibilidade - eu diria sismográfica - para as necessidades materiais de uma população, mas não somente isso. Mais abrangente que outras disciplinas tecnológicas tradicionais, o desenho industrial possui a capacidade de dar uma resposta, em termos materiais, com um sistema de referência cultural, com uma comonente avaliativa e estética".( Bonsiepe, 1980).

A partir dos anos 60, a dimensão formalista, com ênfase nos aspectos estético-formais e na perfeição estética predominou no campo do design. Nos anos 70 e 90 do século passado observou-se um alargamento do escopo, com maior ênfase na relação artefato-usuário. Nos anos 90 e na virada do século XX para o XXI, as fronteiras se tornaram mais fluidas e a complexidade das demandas ambientais adentrou fortemente o campo do design, abrindo novas perspectivas para a pesquisa e para a prática. Neste cenário coloca-se a necessidade urgente de novos modos de pensar, bem como a intensificação da colaboração interdisciplinar.

Os aspectos formais, o talento, o rigor metodológico do projeto não são os únicos instrumentos para responder a magnitude dos problemas hoje enfrentados pelo design. É necessário ir além. Diante dos desafios de preservação e recuperação ambiental anteriormente apontados, o design precisa repensar o uso dos recursos naturais, dos materiais, o uso da energia, mas também considerar o papel das intenções, das prioridades, dos valores em conjunção com sua capacidade criativa.

Acerca das intenções, vale aqui apontar o papel crucial que ela desempenha na racionalidade que preside a produção de conhecimentos da área de ciências sociais aplicadas. O FILÓSOFO Georg Henrik Von Wright, esclarece que a racionalidade das ciências sociais está no âmbito da compreensão da realidade social dos fenômenos sociais e a intencionalidade é uma dimensão extraordinariamente relevante neste 
paradigma, propiciando ao design, entendido como ciência social aplicada, a oportunidade de entrar em um diálogo epistemológico mais complexo com as metodologias e procedimentos das ciências sociais. A intencionalidade aponta para o futuro e está diretamente ligada ao estabelecimento de valores e critérios.

A construção de prioridades e valores é tema central no mundo contemporâneo. Ao repensar o papel da crítica e da teoria, ao repensar o sentindo banalizado hoje dominante desta palavra, reconhecer o design como um dos elementos propulsores de mudança significa inscrevê-lo no âmbito da ética. Assim a discussão ética, e o estabelecimento de valores é fundamental para o design.

Neste momento vale a pena destacar a origem do conceito da ética, que vem do termi grego ethos, que significa 'costume' ou ' modo de ser'.

A ética era disciplina nas escolas da Grécia Antiga que se preocupava com o estudo dos costumes em geral da sociedade e de grupos específicos. A reflexão ética sempre se vinculou como uma pesquisa sobre a natureza do bem moral, na busca de um princípio absoluto de conduta - conhecida como ética geral. A ética geral se relaciona om uma proposta do Sumo Bem e de uma vida virtuosa (ética platônica). Posteriormente, ainda na Grécia Antiga, a discussão sobre a ética ganhou uma visão concreta e finalista, ao dizer, marcado pelos fins da vida cotidiana que deveriam ser alcançados para que o homem alcançasse a felicidade (ética aristotélica).

Após o iluminismo, o ideal geral ético se deslocou para a aplicações práticas do homem em sociedade (ética kantiana), um ideal decorrente da autonomia do homem racional - aquele que age segundo a razão e a liberdade - , proporcionando uma especialização nos estudos da ética (ou das éticas particulares). Tais como a ética profissional, ética política, bioética, ética sexual, e podemos dizer, a ética do designer.

Mas o que é ética $\mathrm{n}$ âmbito do design? É necessário considerar que o design não se restringe a desenhos, representações, protótipos, modelos. Design é também textual, assim como visual. Na produção crítica, da teoria e na construção de valores as palavras são elementos centrais. No design este discurso vem acompanhado da ação criativa que agrega valores e prioridades ao mundo em que vivemos.

No cenário atual, onde o cidadão tornou-se consumidor, com predomínio da massificação, da escassez, do hiperconsumismo e da espetacularização, o design não pode ser agente desresponsabilizador. No caso dos resíduos sólidos, tema sobre o qual venho trabalhado faz muitos anos, os desafios da preservação ambiental vem contemplados de densa legislação ambiental e, $\mathrm{n}$ caso gerar mudanças. É preciso associar a lei, aos valores e as ações criativas do design reflexivo. Capaz de reconciliar ética e estética, capaz de enfrentar o dilema de ações/posições dos designer e criadores versus os efeitos de suas criações no âmbito coletivo. 
Além disso sobre um regime democrático, é fundamental a participação ativa na vida pública, sendo que isso se reflete no trabalho do designer ne sua preocupação com a cidade, com a alteridade, com a ideia de solidariedade e com a promoção de cidadania.

Estar em Minas, no estado que traz a palavra liberdade no centro da sua bandeira é momento muito especial. Especialmente neste início de primavera, após tantas turbulências que atingiram a todos nós, é tempo de recomeçarmos e de abrir novos caminhos, também para o design. Agradecimento efusivo aos organizadores, ao professor Dijon de Moraes, professora Rita Engler, a toda equipe do comitê científico e a cada um de você. Obrigada. 